\title{
Educação ambiental desde o enfoque ciência/tecnologia/sociedade (CTS) - um possível caminho
}

\author{
Cleiva Aguiar de Lima ${ }^{1}$ \\ Universidade Federal do Rio Grande (doutoranda - PPGEA-FURG) \\ Maria Inés Copello ${ }^{2}$ \\ Universid de la República (UdelaR), Uruguai e PPGEA-FURG
}

resumo: Partindo do princípio de que é possível a inserção da dimensão ambiental via CTS (Ciência/Tecnologia/Sociedade) no processo de ensino e aprendizagem de Biologia, se realizou uma pesquisa na qual a questãoproblema foi a análise e a avaliação de uma simulação educativa: "Um caso CTS - Tem sido criada uma vacina contra a AIDS", que foi trabalhada com alunos e alunas do Ensino Médio. Este trabalho caracteriza e fundamenta a pesquisa e discute resultados da mesma em relação a duas categorias de análise: o desenvolvimento da capacidade de argumentação e a construção do pensamento a partir da interação social.

palavras-chave: Enfoque CTS, Competências argumentativas, Conhecimento e interação social.

abstract: Starting from the principle that it is possible to insert the environmental dimension via STS (Science/Technology/Society) in the process of teaching and learning of Biology, we have made an investigation whose central problem was the analysis and the evaluation of an educative simulation: "An STS case - a vaccine against AIDS has been created". It was worked with high school students. This work characterizes and bases the investigation and discusses its results in relation to two categories of

\footnotetext{
1 e-mail: cticle@furg.br

2 e-mail: copello@adinet.com.uy
} 
analysis: development of the capacity to argue and construction of the knowledge from the social interaction.

keywords: STS approach, Argumentative competences, Knowledge and social interaction.

\section{Introdução}

Desde a Conferência Mundial do Meio Ambiente, realizada em 1972, em Estocolmo, discute-se a contribuição da Educação na resolução dos graves problemas ambientais atuais. Primeiro, numa visão conservacionista, porém, posteriormente, essa discussão se amplia, abrangendo a estruturação de um novo paradigma de sociedade. Em Tbilisi, no ano de 1977, ficou estabelecido que a Educação Ambiental deveria ser incorporada em diferentes níveis do ensino e encarada como um redirecionamento das práticas pedagógicas adotadas no ensino formal. Princípios como a interdisciplinaridade, a construção de um processo educativo contínuo e permanente, o exame das questões ambientais do ponto de vista local, regional, nacional e internacional e a participação interativa e cooperativa em contraponto à dominação do professor/a e à passividade do aluno/a precisariam ser assumidos. As questões ambientais deveriam ser consideradas na sua totalidade, incluindo os aspectos culturais, científicos, políticos, éticos, tecnológicos, econômicos, culturais e ecológicos, tendo em conta também a perspectiva histórica.

Esta Educação Ambiental, de acordo com Brügger (1999), não deve ser concebida como um complemento da Educação: ela perpassa e constitui todo o currículo escolar, entendido numa nova concepção. Assim, a escola deverá ser orientada para uma proposta pedagógica interdisciplinar que em nossa visão supera totalmente a mera reunião dos professores para trabalhar um assunto em comum. Assumimos a interdisciplinaridade no dizer de Fazenda (2000) como a necessidade de "cumplicidade" frente a um desafio comum, "na convergência de olhares" que leva à interação. Nesse sentido, a interdisciplinaridade 
poderá ocorrer no grupo dos professores da escola, bem como em relação a um professor/a, ele/a mesmo/a interdisciplinar (capaz de múltiplos olhares) e interatuante com seus alunos, construindo objetivos com cumplicidade e com co-responsabilidades.

Conjuntamente com as questões pedagógicas, vamos considerar ainda as intrincadas relações entre a ciência, a tecnologia e a sociedade, uma vez que o aumento exponencial do conhecimento científico e do aprimoramento tecnológico caracteriza as sociedades atuais. Nos últimos anos, houve um enorme incremento nos avanços científicos e tecnológicos. Embora muitos tenham sido catastróficos, como, por exemplo, as armas nucleares e químicas, também muitos contribuem positivamente para a sociedade. Por exemplo: os aparatos que permitem diagnósticos de doenças, os que possibilitam a coleta e o tratamento de informações, enfim, os que facilitam e melhoram a vida (GOUVÊA; LEAL, 2001). Destacam-se ainda as invenções tecnológicas que são capazes de reverter ou minimizar os efeitos danosos provocados pelo homem na natureza.

A discussão desta temática não é recente. Os movimentos sociais das décadas de 1960 e 1970 contribuíram para que a ciência e os avanços tecnológicos passassem a ser questionados e reorientados. No bojo desses questionamentos, emerge o movimento CTS, que se constitui numa linha de trabalho de caráter interdisciplinar e que discute a natureza social do conhecimento científico e tecnológico e suas implicações nos diferentes âmbitos econômicos, sociais, ambientais e culturais das sociedades ocidentais (OSÓRIO, 2002).

Numerosos autores, como é o caso de Osório, apontam para a incorporação de uma abordagem CTS no ensino formal. Propõe-se que a educação num enfoque CTS tenha como objetivo a alfabetização científica e tecnológica dos cidadãos. O movimento CTS questiona o distanciamento entre o desenvolvimento científico e tecnológico e o bem-estar social. As melhorias da tecnologia fundamentadas nos avanços da ciência não deveriam contribuir para melhorar a qualidade de vida das atuais gerações? Sabemos que sim, mas o que se observa é o agravamento dos problemas socioambientais. Por quê? 
Segundo Santos (1998), isso se vincula à ciência moderna, que ensinou a rejeitar o senso comum e a considerar válido apenas o que é passível de experimentação, quantificação e generalização. Desse modo, perpetua a idéia de ciência objetiva, neutra e alheia ao uso que a sociedade faz dela. Essa visão simplista, que não leva em conta os aspectos históricos nem os atuais condicionantes sociais das atividades científico-tecnológicas, faz com que tenhamos uma abordagem inadequada das relações entre ciência e tecnologia, bem como de suas implicações sociais (VALDÉS et al., 2002). Portanto, entendemos que estabelecer claramente as relações entre ciência, tecnologia e sociedade deva ser uma das preocupações do ensino atual, que, para isso, pode buscar apoio no movimento CTS.

Partimos da premissa de que, ao se propor uma discussão democrática, aberta e sem preconceitos da ciência e tecnologia e suas implicações na melhoria da qualidade de vida de todos, está se fazendo Educação Ambiental. Ou seja, estão sendo formados cidadãos que de posse de informações adequadas sobre os avanços científicos e tecnológicos atuais possam discutir, se posicionar e inclusive propor ações sobre a validade e a adequação desses avanços para suas vidas.

Conforme Amorim (1997), a abordagem CTS no ensino exige mudanças tanto na escolha dos temas quanto das metodologias de ensino e de aprendizagem. Como então incorporar a perspectiva CTS nos conteúdos, tendo como objetivo desenvolver a capacidade de avaliar o uso social da ciência e tecnologia? Como modificar as abordagens metodológicas nas atividades de ensinar e de aprender a fim de desenvolver, entre outras, a capacidade de reflexão, de argumentação, de trabalho cooperativo, de forma a dar condições para um posicionamento crítico frente à ciência, à tecnologia e ao uso social das mesmas?

$\mathrm{Na}$ disciplina de Biologia, pode-se discutir o papel da ciência, dos cientistas, da tecnologia e suas relações com a sociedade. Isso surge tanto ao serem tratados temas de biologia pura como outros mais aplicados, como é o caso da biotecnologia, tratamento e prevenção das doenças que passam por decisões políticas de melhoria no saneamento básico, criação de novos medicamentos ou vacinas, entre outros. 
É com base em reflexões como as expressadas até aqui que nos propusemos a desenvolver uma pesquisa que tem por objetivo analisar uma situação de trabalho educativo que procura inserir a dimensão ambiental no currículo por meio de uma proposta didática, na área da saúde. Tendo assumido como princípio a validade da contribuição da linha de trabalho CTS para a Educação Ambiental, propomos a ambientalização do currículo de Biologia pela vertente CTS. Escolhemos como estratégia aplicar em turmas de Biologia para as quais lecionamos a proposta didática: Um caso CTS: "Tem sido criada uma vacina contra a AIDS". Nessa proposta didática, adaptada de Gordillo (2001), se estabelece a simulação de uma controvérsia pública de relevância social sobre um tema técnico-científico polêmico: uma vacina contra a AIDS. A caracterização completa da controvérsia implica a existência de grupos sociais (posicionando-se a favor ou contra) que, numa suposta Conferência Internacional, debaterão sobre a liberação ou não dos ensaios finais da vacina.

O trabalho com essa proposta didática ${ }^{3}$ (PD) teve início com a leitura de uma notícia fictícia, porém verossímil, incorporada em um jornal local, anunciando o êxito dos testes iniciais com uma vacina contra a AIDS e que teria sua liberação para a comercialização após testes em humanos, no caso, crianças africanas menores de três anos. Tal notícia desencadeou a dinâmica da $\mathrm{PD}$, cujo ponto culminante foi a simulação da Conferência Internacional para debater o tema e decidir a liberação ou não dos ensaios finais com a vacina.

Após a discussão da notícia, cada aluno preencheu um questionário com questões sobre o HIV, sobre vacinas e sobre a AIDS. Posteriormente, a turma dividiu-se em seis grupos: Comitê encarregado de organizar, mediar e dirigir a conferência; Corporação de Laboratórios; ONG Prevenção e Solidariedade; Departamentos de Saúde; Comitê de Investigadores e ONG Saúde e Moral ou ONG Familiar, responsáveis por elaborar argumentos para defender a postura favorável ou contrária à liberação dos testes com a vacina.

${ }^{3} \mathrm{O}$ texto incorpora a PD ao se referir a proposta didática. 
O trabalho, tendo como questão de pesquisa a compreensão das práticas pedagógicas como produtoras de conhecimentos, sentidos e/ou significações, buscou analisar a construção da capacidade de avaliar o uso social da ciência e tecnologia, assim como seus limites e compromissos em função do social. Neste artigo, serão abordados dois dos três parâmetros que a pesquisa utiliza como categorias de análise (elaboradas posteriormente à coleta de dados), que são "o desenvolvimento da capacidade de argumentação" e "a construção do pensamento a partir da interação social": constituição da sala de aula como uma Comunidade de Aprendizagem. $\mathrm{Na}$ estrutura trabalhada, o professor mantém um papel de orientador dos processos da aula, porém desaparece enquanto figura central no acontecer das situações e os alunos/as passam a ter um intenso protagonismo. A proposta procurou compreender o processo educativo, considerando:

- Se e como os alunos/as têm desenvolvido a capacidade de argumentação;

- Se e como as interações sociais têm influído na estruturação do conhecimento dos alunos e alunas;

- Ainda: como a professora pesquisadora tem participado no processo educativo; processo de auto-reflexão sobre os diferentes papéis em que se localiza e implica no processo: professora, pesquisadora, pessoa...

\section{Fundamentação teórica}

\section{Tríade CTS: ciência, tecnologia e sociedade}

A discussão dessa temática iniciou-se em meados do século XX quando se percebeu que a ciência e a tecnologia, além de não estarem conduzindo linear e automaticamente ao desenvolvimento do bemestar social, estavam colocando em risco a humanidade como um todo (AULER; BAZZO, 2001).

Segundo Santos e Mortimer (2001), o movimento CTS se estrutura em contraposição ao pressuposto cientificista de que a ciência 
é neutra, infalível e inatingível, resultando em um novo enfoque da ciência e tecnologia. Constitui-se numa linha de trabalho de caráter interdisciplinar que discute a natureza social do conhecimento científico e tecnológico e suas implicações nos diferentes âmbitos econômicos, sociais, ambientais e culturais das sociedades ocidentais (OSÓRIO, 2002). Para Bazzo (2002), talvez seja um dos maiores paradoxos destes séculos o fato de que, por um lado, observamos desenvolvimentos tecnológicos e científicos promissores e, por outro, o agravamento de problemas como: fome, guerras, distribuição de renda e fortes degradações ambientais.

Acreditamos que essa contradição possa ter vinculação com a falta de reflexões sobre o papel da ciência e da tecnologia e sua adequação às questões sociais, como também à separação do cognitivo, do valorativo e do atitudinal no ensino. Diante disso, surgem algumas questões: como fazer com que as pessoas tenham acesso às informações e possam se posicionar sobre os avanços científicos e tecnológicos e suas implicações sociais? Como trabalhar na sensibilização para com valores, atitudes e comportamentos que venham ao encontro das reflexões feitas? Como inserir essa discussão na formação acadêmica dos jovens, sobretudo sabendo que muitos deles no futuro não escolherão carreiras científicas?

Muitos autores (OSÓRIO, 2002; VALDÉS et al., 2002; AMORIM, 2001; AULER; BAZZO, 2001) apostam na incorporação de uma abordagem CTS no ensino formal. Osório propõe que a educação, num enfoque CTS, tenha como objetivo a alfabetização científica e tecnológica dos cidadãos.

Em nosso ponto de vista, a alfabetização como sinônimo de apropriação dos conceitos pertinentes à ciência e à tecnologia perde o sentido se ficar apenas em nível informativo. Certamente, os saberes científicos e tecnológicos são necessários, mas é importante ter claro que a informação só tem sentido se possibilitar a tomada de decisão a partir da reflexão crítica nas distintas situações cotidianas, essencial num mundo cada vez mais globalizado e tecnificado. Ainda é importante que seja difundida a idéia de que a ciência não é neutra e que as conquistas 
científicas atuais são o resultado de equipes de cientistas consorciados. Discutir isso é mais que alfabetizar em ciência e tecnologia.

Seguramente, é possível estabelecer um elo entre educação em CTS e Educação Ambiental, uma vez que consideramos esta como uma educação política que, segundo Reigota (1998), deve preparar os cidadãos para agir, após refletir "por que" fazer, antes de "como" fazer, e então contribuir com a formação de indivíduos críticos aptos a agirem responsavelmente.

Sem dúvida, todas essas questões nos apontam para o papel da escola, cada vez mais solicitada a interagir com a sociedade para preparar integralmente o aluno, dando-lhe condições de compreender e agir no mundo.

\section{A Educação ambiental: um viés para repensar o ensino médio e o papel da biologia na ambientalização escolar}

A transição paradigmática que estamos atravessando pressupõe uma mudança profunda no campo educacional. Há consenso de que a Educação Ambiental seja uma alternativa válida que poderá acompanhar diferentes propostas. Muñoz (1996) propõe que a Educação Ambiental deve, entre outras finalidades,

capacitar as pessoas para trabalhar conflitos e para integrar conhecimentos, competências, valores, atitudes e ações buscando a transformação de hábitos consumistas e condutas ambientais inadequadas. É uma Educação para a mudança. (MUÑOZ, 1996, p. 28, grifo da autora, tradução nossa).

Para isso, acreditamos na transversalidade como forma adequada e possível de implementar a dimensão ambiental na realidade atual do ensino formal, pois, considerando que nem todos os envolvidos estarão dispostos a mudanças radicais, tal proposta, ao mesmo tempo em que rompe com velhos paradigmas, permite a passagem gradual rumo ao novo, no qual os princípios preconizados pela educação ambiental sejam trabalhados. 
Há um consenso de que a educação ambiental, mediante seus objetivos e princípios, seja uma alternativa válida e que poderá acompanhar diferentes propostas. Nos alinhamos na concepção de que a EA mais condizente é aquela na qual a capacitação para a ação responsável é um caminho a ser trilhado. Isso está ligado à compreensão dos conflitos socioambientais, o que implica uma participação responsável, crítica e fundamentada, que leve em conta a pluralidade de idéias na busca de uma sociedade justa, solidária e fraterna. Nesse sentido, a transformação social passa pela reflexão e pela atuação de cada um e dos que têm o poder das decisões (GARCIA, 2002; SANMARTI; PUJOL, 2002).

No caso de currículos "ambientalizados", se propõe também princípios metodológicos favoráveis e adequados a EA, como a visão global dos temas, que devem situar-se numa perspectiva sistêmica, o tratamento interdisciplinar, o conhecimento dos conceitos prévios de alunas e alunos, a metodologia ativa e participativa e as estratégias de investigação e de resolução de problemas. (1996, p. 63, grifo da autora, tradução nossa).

Diante da realidade das escolas, acredita-se que a ambientalização do processo do ensino e da aprendizagem, que, idealmente, deve atingir toda a instituição educativa, poderá começar ainda que seja por uma disciplina, no nosso caso a biologia. Consideramos esta uma forma possível de implementar a educação ambiental no contexto atual do ensino médio. A imersão ou impregnação da dimensão ambiental no currículo encara uma nova proposta de ensino e possibilita que os objetivos da Educação Ambiental sejam atingidos de modo crescente, reorientando o processo de ensino e de aprendizagem adotado atualmente na maioria das escolas.

A ambientalização da disciplina de biologia será entendida, então, com base no discutido anteriormente, como a impregnação dos princípios da EA - interdisciplinaridade, visão sistêmica, participação interativa, processo educativo contínuo e permanente - que aponte para uma nova maneira de encarar os problemas e, por conseguinte, propor 
soluções. A biologia, como as demais disciplinas científicas, tem um relevante papel quando insere a relação entre ciência, tecnologia e sociedade numa abordagem reflexiva que possibilita aos alunos perceberem como esses três aspectos podem contribuir ou não para a melhoria da qualidade de vida das pessoas, segundo o modelo que apresentam. Isso implica ter em conta os princípios básicos da educação ambiental, os quais estão relacionados com uma abordagem diferenciada sobre o ambiente, sendo este considerado em seus múltiplos aspectos e também em consonância com as questões ambientais, que devem ser vistas de fato como questões socioambientais, uma vez que não existe sociedade sem ambiente. Finalmente, tais princípios estão também relacionados com o papel dos seres humanos, integrantes desse ambiente, e com a importante tarefa de contribuir para sua melhoria.

Assim, é possível discutir problemas como pobreza, doenças, desemprego, exclusão social, globalização da economia e sobre os paradoxos entre desenvolvimento tecnológico e produtividade, no que diz respeito ao modo como a ciência e a tecnologia respondem às questões mais urgentes. Certamente, acreditamos nisto como um caminho a ser trilhado até que se atinja a utopia concretizável de trabalharmos em plenitude a interdisciplinaridade.

A escolha da tríade CTS permeando o ensino de biologia justifica-se também porque a problemática tecnológica contemporânea está marcada pela falta de reflexões éticas sobre suas finalidades, e, como educadores, devemos refletir sobre os valores que estão definindo as prioridades e os impactos tecnológicos no mundo atual.

\section{Delineamento metodológico da pesquisa}

Esta pesquisa optou por se delinear como um estudo de caso etnográfico, considerando-se que isso vinha ao encontro da opção de analisar uma simulação didática desenvolvida numa situação real de sala de aula. O estudo de caso torna possível, segundo André (1995, p. 47), "o estudo aprofundado de uma unidade em sua complexidade e em seu dinamismo próprio, fornecendo informações relevantes para tomada de decisão". 


\section{Coleta de dados}

A coleta de dados, inserida num contexto do Ensino Médio, visou, por um lado, à obtenção de documentação capaz de permitir a análise da pesquisa e, por outro, obter os materiais necessários para promover a avaliação dos alunos. Os dados foram coletados a partir do acompanhamento e observação sistemática da professora pesquisadora em todas as turmas e incluíram, além dos documentos escritos: anotações de campo, diário da professora e dos alunos, trabalho escrito pelos alunos e fitas de vídeo obtidas pelas filmagens das aulas em duas das quatro turmas nas quais foram desenvolvidas as atividades.

\section{Análise dos dados}

Foi realizada uma análise de conteúdo, o que, segundo Pereira L. (1998, p. 94), “(...) é de realizar uma descrição analítica, sistemática, com objetividade cientifica, propiciar a compreensão qualitativa do conteúdo das mensagens".

As categorias não foram estabelecidas a priori. A partir de uma análise preliminar global, foram se delineando as categorias de análise, feita a unitarização dos dados e destacadas as unidades de significado, que foram inter-relacionadas, encaminhando-se assim a divisão em três categorias, a saber: a construção da capacidade de argumentação: senso crítico, capacidade de comunicação e de fundamentação na tomada de decisões, no processo de aprendizagem dos alunos; a perspectiva da constituição da sala de aula como uma Comunidade de Aprendizagem, em que a interação social estimula a construção do conhecimento dos alunos, das alunas e da professora, bem como possibilita o exercício da solidariedade e da cooperação; e a professora frente ao desafio que significa se constituir em pesquisadora de sua prática.

A partir dessas categorias, foi realizada uma análise qualitativa interpretativa que não se centralizou nos dados de cada turma, mas numa visão geral, já que o objetivo foi o de compreender o processo como um todo e não de forma comparativa em relação às diferentes turmas 


\section{Argumentação: Exercício da Dialogicidade}

A argumentação, um processo de comunicação, desencadeia uma série de mecanismos a fim de construir teses, elaborar idéias, assumir posições e, por conseqüência, permitir explicitar conhecimentos e concepções e, o que se julga mais importante, possibilita o diálogo. $\mathrm{O}$ que se pretendeu com o estímulo à argumentação foi que os alunos se tornassem capazes de dialogar, de lidar com informações, com suas crenças, com seus valores, dúvidas e incertezas, de modo a analisar, comparar e fundamentar uma determinada escolha, porque se acredita que a escola, mais do que informar, precisa investir na formação dos alunos, e a disciplina de Biologia pode, ao mesmo tempo em que aborda conteúdos conceituais, não descuidar de proporcionar atividades que desenvolvam atitudes e permitam a vivência de certos procedimentos, úteis para a atuação dos jovens no seu meio social.

Entende-se a argumentação como um processo comunicativo no qual o interlocutor defende uma certa idéia e que, como asseguram Perelman e Olbrechts-Tyteca (2002), pressupõe a existência de um contato intelectual no encontro com o Outro e com outras idéias. Possibilita o exercício do diálogo, do respeito às idéias divergentes e às singularidades de cada indivíduo. Como os alunos registram no diário semanal do grupo: Esse trabalho contribuirá muito para nosso futuro, pois aprendemos a trabalhar, a respeitar, e divergir com colegas de "trabalho".

Salienta-se que, com a argumentação, mesmo que de alguma forma haja pretensão de convencer que a postura adotada é a melhor, aqui colocamos a ênfase no processo de construção da capacidade argumentativa e não na qualidade do argumento final. Ou seja, a ênfase é dada ao diálogo, que consiste em construir com os demais, e não ao debate entendido como confronto, no qual haja vencedores $\mathrm{e}$ derrotados. Mesmo porque, numa simulação com fins educativos, deve ser acentuado o compartilhar opiniões e os dados organizados para o esclarecimento dos aspectos que a questão proposta envolve. E assim, a busca do resultado constitui-se em um dos elementos que desencadeiam e motivam o trabalho. 


\section{A escolha entre idéias antagônicas}

A argumentação, uma vez que supõe a construção de um raciocínio para chegar a alguma conclusão, é mais do que enumerar fatos e fazer descrições. Supõe a ocorrência de pelo menos duas posições antagônicas, que podem ou não estar explícitas em um debate, e a escolha de um ponto de vista a defender, neste caso: a liberação ou não dos ensaios finais com a vacina.

No trabalho proposto, os alunos, ao terem que adotar um posicionamento sobre os ensaios finais com a vacina, explicitaram as posições antagônicas que foram amplamente defendidas durante a Conferência. Também a tomada de posição envolveu a negociação entre os indivíduos que compunham o grupo, como ficou registrado num dos diários semanais das equipes: $O$ trabalho serviu para expor nossos sentimentos e pensamentos e opiniões onde surgiram idéias opostas ao que temos que defender.

As razões para o posicionamento defendido ficaram a critério de cada equipe, que pôde escolher a idéia que iria defender e em que aspectos sustentaria o posicionamento adotado. Dessa forma, a discussão sobre vírus e vacinas pôde ser realizada a partir da perspectiva teórica buscada pelos alunos e não pela perspectiva da professora. E isso, sem dúvida, foi um aspecto relevante para o envolvimento dos alunos no trabalho.

A decisão final do debate coube, em cada turma, ao Comitê. De certo modo, em nenhuma das quatro turmas, houve a aprovação da continuidade dos testes conforme estava proposto. A turma A não aprovou a continuidade dos testes. E mesmo que nas demais turmas os ensaios finais com a vacina fossem liberados, os alunos impuseram um conjunto de condições que, ao descaracterizar a proposta inicial, permite afirmar que essa fase dos testes da vacina foi rejeitada por todas as equipes.

Tais resultados apontam para a preocupação dos alunos com princípios éticos de valorização da vida ao rejeitarem a proposta de os testes serem feitos com crianças africanas menores de três anos, mediante pagamento em dinheiro. Mostram ainda como os alunos se engajaram no trabalho, de modo cooperativo e responsável, 
estabelecendo uma discussão séria sobre as relações entre a ciência, a tecnologia e a sociedade.

\section{A construção dos argumentos e a discussão CTS}

Para construir argumentos, é necessário organizar informações a fim de justificar uma determinada escolha, possibilitando estabelecer a discussão das idéias a serem defendidas. Isso permite aos alunos utilizarem instrumentos como a linguagem escrita, estratégias de leitura, de coleta e de organização de dados, bem como desenvolver habilidades de expressão oral, como o exercício de falar perante um auditório que, mesmo constituído na maior parte pelos colegas e pela professora da turma, possibilita a experiência de falar em público (BERNARDO, 2000).

A busca de subsídios teóricos sobre o tema motivou os alunos a entrarem em contato com diferentes instituições relacionadas à saúde, como o Grupo de Apoio e Prevenção à AIDS (GAPA), o Hospital Universitário e um dos Postos de Saúde do Município, bem como a Igreja Católica, tendo sido realizada neste último caso uma entrevista. Também uma das equipes realizou uma enquete na comunidade.

Isso possibilitou aos alunos conhecer as instituições envolvidas com a prevenção da AIDS, esclarecer dúvidas e assim enriquecer o trabalho com os dados e materiais obtidos, o que promoveu a troca de idéias, fortaleceu o diálogo e a abertura para o novo. Contribuiu também para que fossem extrapolados os limites físicos da escola, ao envolver pessoas externas ao contexto escolar.

A criatividade, a iniciativa, a disponibilidade e o envolvimento dos alunos com as tarefas solicitadas ficaram explícitas quando, por exemplo, tornaram-se autores de um acordo fictício (com a ONU) que, ao mesmo tempo em que contribuiu para a defesa da idéia adotada pela equipe, permitiu o exercício da imaginação, capaz de surpreender os colegas da turma.

Assim, proporcionar atividades que exijam do aluno a construção de argumentos para os quais ele mesmo tenha que buscar informações com o fito de dar suporte teórico às suas idéias e ao 
posicionamento a ser defendido constitui-se numa maneira de garantir a participação do aluno na sua própria aprendizagem. Também garante a autonomia, estimula a iniciativa e a organização, aspectos necessários para o objetivo central da EA: capacitar para a ação responsável.

Os pontos analisados mostraram que as equipes embasavam seus argumentos em diferentes razões: social, econômica, científica e ética. Isso indica que o aspecto biológico não foi único, nem preponderante, mesmo tendo sido evidenciado nas questões concernentes aos vírus e às vacinas, próprias dos aspectos científicos.

Os alunos extrapolaram também os limites teóricos da disciplina de Biologia, mostrando que, mesmo que toda a sua escolarização até aqui tenha contribuído para a criação de "gavetas mentais", separando cada conteúdo trabalhado, suas mentes continuam capazes de romper com a compartimentalização estanque das disciplinas.

Percebe-se que a construção dos diferentes argumentos pelos atores sociais envolvidos na polêmica, ainda que tenham como base aspectos distintos, giraram em torno de pontos em comum: a situação dos doentes, da África, dos procedimentos científicos e da prevenção, envolvendo a discussão das relações CTS. As equipes fizeram uma análise crítica do papel da ciência e da tecnologia e da sua relação com a sociedade. As diferentes posturas consideraram principalmente a questão das crianças africanas e a preocupação com a condição de cobaias a que seriam submetidas as pessoas que participariam dos testes.

Foram verificados avanços na formação dos alunos envolvendo atitudes e procedimentos quanto à: desinibição para falar diante dos colegas, capacidade de relacionamento afetivo, cooperativo e solidário nos grupos, entre outros. Já a aprendizagem conceitual, ainda que evidenciada, fica em um patamar menor ao que era esperado: os argumentos apresentavam uma fundamentação teórica um pouco débil. $\mathrm{Na}$ elaboração do documento final, os alunos recolheram material para essa fundamentação, indicaram as referências consultadas, tanto nos protocolos quanto no debate oral por ocasião da Conferência, porém, faltou maior claridade a respeito da referência que estavam adotando para fazer suas declarações. Não expuseram as fontes concretas que 
subsidiaram seus dados, o que resultou também numa discussão das relações CTS que não atingiu a profundidade a que o trabalho se propunha. Temos consciência de que esse era um dos desafios difíceis de atingir e os resultados não levam à negação da possibilidade que tem essa forma de trabalho para a construção de argumentações com sérios fundamentos conceituais.

\section{Comunidade de aprendizagem: efetivação da construção do conhecimento na interação social}

$\mathrm{Na}$ abordagem sócio-histórica de Vygotsky, o ser humano adquire humanidade nas relações sociais mediadas por sistemas simbólicos, se constituindo ao longo de um percurso histórico e sendo, portanto, um ente em construção.

Por isso, a abordagem de Vygotsky sempre envolve a interação social no processo de aprendizado. Segundo Oliveira (1993, p. 57): "Em Vyotsky, justamente por sua ênfase nos processos sócio-bistóricos, a idéia de aprendizado inclui a interdependência dos indivíduos envolvidos no processo". Ainda segundo a autora, o aprendizado para Vygotsky pressupõe o contato do indivíduo com a realidade, com o ambiente e com as outras pessoas e a conseqüente aquisição de informações, habilidades, atitudes e valores.

Sendo assim, o processo educativo ocorre nas e pelas relações sociais. É importante ter claro, então, que a qualidade das relações sociais que ocorrem na escola é fundamental para o aprendizado, bem como para o desenvolvimento do aluno enquanto pessoa.

Nesse caso, o professor deve ser facilitador da aprendizagem na medida em que faz o elo entre a teoria e a realidade, dando condições para que o aluno, nas mais distintas interações, construa seu próprio conhecimento. Desse modo, deve haver preocupação em não adotar uma prática repetitiva e não limitar o diálogo com os discentes ao espaço da sala de aula nem a conteúdos específicos. Enfim, promover diversas situações e interações que superem a rotina de transmissão e recepção de conteúdos conceituais, prática de ensino tradicional que é predominante na maioria das escolas há muito tempo. 
Pretende-se caracterizar o desenvolvimento da PD e a constituição da sala de aula como uma Comunidade de Aprendizagem (CA), identificando os possíveis pontos de convergência dessa perspectiva pedagógica no trabalho desenvolvido.

\section{A importância do grupo na constituição de uma CA}

Orellana (2002) considera a Comunidade de Aprendizagem uma estratégia pedagógica que tem, por princípio, a construção social do conhecimento e que abre novas perspectivas educativas, particularmente em EA. O processo de aprendizagem que gera o saber ser, o saber viver e o saber fazer está embasado na sinergia de um grupo organizado, no qual a participação ativa, a cooperação, o diálogo dos saberes, a complementaridade, a negociação e a ação reflexiva comum são elementos fundamentais.

A transcrição de fragmentos dos diários dos alunos aponta para a evidência de que alguns desses elementos indispensáveis na concretização das CA foram vividos:

Incentivados pela responsabilidade de coordenar um evento de importância internacional, os integrantes tiveram grande participação na realização do trabalho, dando idéias, tomando iniciativas e expondo seus pensamentos.

Nossa equipe pensa que este empenho que tivemos neste trabalho, será muito importante para o nosso futuro em nossas vidas, pois (nos) tornaremos mais aguerridos do que já somos para conquistarmos algo.

A partir desse fragmento, pode-se inferir sobre a importância conferida ao grupo e à constituição de uma CA. O grupo toma consciência de seu papel no trabalho e na sociedade e se mantém unido para realizar as tarefas propostas. Há um rompimento com o individualismo e há a valorização da equipe, capaz de agir como uma unidade, o que aponta para a efetivação de uma nova postura diante do ato de aprender. A percepção de que a escola é um lugar de vida e que as experiências escolares podem servir de bagagem para o saber viver 
ficou explícita no relato dos alunos, que, dessa forma, sentiram-se realmente inseridos na comunidade escolar.

Foi possível perceber vários aspectos reconhecidos como positivos pelos alunos. Por exemplo, algumas situações almejadas pelos professores, como o cumprimento das tarefas e a empolgação dos alunos, em muitas ocasiões difíceis de ocorrer, quando o trabalho é feito no grande grupo, parecem ser facilmente obtidas nos pequenos grupos, os quais, gerenciados pelos alunos, organizaram a seu modo o tempo, a forma de resolver as tarefas e a participação de cada um na equipe.

\section{O diálogo como ponto central da ação em uma CA}

O relato abaixo, extraído do diário de um dos grupos, explicita por que o diálogo é considerado ponto central numa CA:

(...) as decisões foram tomadas em conjunto, que a opinião de cada integrante teve grande importância e foi levada em consideração e que foram considerados os pensamentos, a tendência e as conclusões de cada um para que as tarefas fossem divididas corretamente e para que o aproveitamento fosse total, já que fazemos melhor aquilo que gostamos, desde que isto seja possível.

Nesse grupo, nota-se a preocupação em aliar a necessidade de realizar as tarefas e o prazer em realizá-las, e, como forma de obter o consenso e o acordo nas decisões para que todos ficassem satisfeitos, os alunos recorreram ao diálogo.

Essas idéias vão ao encontro do que Orellana (2002) considera quando aponta o diálogo como um ato criativo necessário para o intercâmbio de idéias, que se constitui na essência da educação. Assim, na PD desenvolvida, observou-se, pelos relatos nos diários, a importância que os alunos atribuíram para a troca de idéias, para a negociação e para o diálogo.

Considera-se de fundamental importância que o diálogo se estabeleça não apenas entre os alunos, mas entre estes e o professor, já 
que isso se constitui na essência de uma CA, por fortalecer as relações interpessoais, facilitando a aprendizagem. Convém destacar que o diálogo não ficou restrito às atividades inerentes ao trabalho desenvolvido em aula nem ao grupo de trabalho: estabeleceu-se em outros momentos. Destacamos as entrevistas com diferentes organizações sociais da comunidade e o momento da Conferência na qual o debate se estabeleceu em um clima de dialogicidade tanto entre os grupos com posições antagônicas quanto entre eles e os demais alunos presentes.

Com isso, entendemos que são observados pontos de intersecção entre a CA e a ambientalização da escola, uma vez que a reorientação das relações do homem consigo mesmo e com a natureza constitui-se em um dos princípios básicos almejados pela escola quando pretende a inserção da EA no ensino formal, e as CA, por diversas razões, contribuíram para isso.

\section{As interações numa CA: a importância da afetividade, da convivência e do respeito mútuo}

Acredita-se que as CA possibilitam que a relação entre o professor e os alunos e dos alunos entre si ocorra com companheirismo e colaboração, bem como com afetividade, com respeito mútuo e com diálogo, o que permite a adoção de decisões consensuais.

Permitem aos alunos mais espaço para exercer a convivência com os colegas (restrita aos intervalo de classe na aula tradicional). Reforça-se, portanto, a importância de desenvolver as CA que favoreçam trabalhos em grupos, que possibilitem, nas interações, a ressignificação de posições perante os assuntos discutidos, por meio do diálogo e do respeito às idéias divergentes. Aprende-se a conviver com a diversidade cultural, que implica diversidade de pensamentos e de valores, trocar experiências, a socializar dúvidas e a compartilhar saberes vivenciados nas interações.

Nesse sentido, entende-se que as Comunidades de Aprendizagem situam-se como pontos de resistência à deteriorização das relações sociais, que tantas conseqüências nefastas tem trazido para a humanidade, 
sobretudo com o agravamento dos problemas socioambientais na contracorrente dos avanços científicos e tecnológicos.

\section{Algumas conclusões...}

Num dos diários de alunos, se expressa:

Consideramos este trabalho um excelente exercício para aprendermos 'o poder da argumentação', pois é de extremo consenso da equipe, que o trabalho contribui de forma significativa para o nosso futuro, nele são encontrados fatores indispensáveis para o nosso desenvolvimento intelectual como: defesa de idéia, jogo de palavras, manipulação da verdade, busca de conhecimentos e muito mais. Este é um trabalho que estamos adorando fazer e desenvolver, pois se trata da discussão de um assunto muito polêmico que pretende chegar a um resultado.

De nossa parte, a primeira idéia a ser retomada é a crença de que as relações dos seres humanos entre si e com os demais seres estão atualmente de tal modo comprometidas que é indiscutível a necessidade de retomá-las numa nova perspectiva. Isso tem justificado as inúmeras discussões sobre o papel da Educação Ambiental em novas propostas de ensino e a preocupação que se percebe com os rumos das práticas pedagógicas nas escolas. Aponta-se a ambientalização do processo do ensino e da aprendizagem como uma possibilidade de redirecionar as práticas pedagógicas

Como segunda idéia, argumenta-se que o desenvolvimento de uma atividade na área da saúde, envolvendo a discussão CTS, foi entendida como uma significativa contribuição para a ambientalização do processo de ensino-aprendizagem de Biologia, porque:

- permitiu desmistificar o referido processo de ensinoaprendizagem de Biologia, geralmente entendida como ciência compartimentada, especializada e separada das questões sociais, já que os alunos extrapolaram os limites teóricos da disciplina ao buscar argumentos que envolviam questões tecnológicas, políticas, econômicas, sociais, éticas e religiosas, além das científicas; 
- possibilitou, ao abordar um tema atual, trabalhar competências que permitam ao aluno pensar o mundo e agir no mesmo, como, por exemplo, a capacidade argumentativa;

- criou situações como a simulação da Conferência, para que os alunos percebessem que o conhecimento é imprescindível para lidar com distintas situações cotidianas;

- possibilitou aos alunos exercitarem a constituição de uma Comunidade de Aprendizagem na sala de aula, na qual as relações interpessoais e a construção do conhecimento foram potencializadas;

- possibilitou aos alunos um envolvimento efetivo com a proposta, evidenciado pelo aumento da motivação e pela valorização de outros aspectos (procedimentos, valores e atitudes), em que "a nota" foi relegada a segundo plano;

- ampliou os aspectos científicos específicos da Biologia, que foram considerados segundo os princípios da Educação Ambiental, na perspectiva do movimento CTS, não reduzindo a abordagem ética e política das questões ambientais, necessariamente complexa e multifacetada, exclusivamente aos seus aspectos biológicos.

Por fim, destaca-se um dos maiores desafios para educadores comprometidos e cientes da necessidade de incorporar a EA no ensino formal: acreditar, ter esperança e poder de decisão e, a partir disso, procurar contribuir, mesmo que seja com um primeiro passo, para que as mudanças aconteçam, entendendo que este compromisso como educadores não pode ser um ponto final a ser atingido, senão uma forma cotidiana de viajar no dia-a-dia.

\section{Referências bibliográficas}

AMORIM, Antonio Carlos. R. O Ensino de Biologia e as relações entre Ciência/Tecnologia/Sociedade: o que dizem os professores e o currículo do ensino médio? In: Encontro Perspectivas do ensino de biologia, 6, 1997, São Paulo. Coletânea. Campinas: UNICAMP. Graf. Central, 1997. p. 74-77. 
- O que foge do olhar das reformas curriculares: nas aulas de Biologia, o professor como escritor das relações entre ciência, tecnologia e sociedade. Revista Ciência \& Educação, São Paulo, v. 7, n. 1 p. 47-66, maio 2001.

ANDRÉ, Marli E. D. A. Etnografia da prática escolar. Campinas: Papirus, 1995.

AULER, Décio; BAZZO, Walter A. Reflexões para a implementação do movimento CTS no contexto educacional brasileiro. Revista Ciência \& Educação, São Paulo, v. 7, n.1, p. 1-14, maio 2001.

BAZZO, Walter A. A pertinência de abordagens CTS na educação tecnológica. Revista Iberoamericana de Educación, Madrid, n. 28, enero-abril 2002. Disponível em: <www.campus.oei.org/salactsi/revista/rie28a03.htm> Acesso em: 11 jul. 2002.

BERNARDO, Gustavo. Educação pelo argumento. Rio de Janeiro: Rocco, 2000.

BRÜGGER, Paula. Educação on adestramento ambiental? $2^{\mathrm{a}}$ ed. Florianópolis: Letras Contemporâneas, 1999.

FAZENDA, Ivani C. A. Integração como proposta de uma nova ordem na educação. In: ENCONTRO NACIONAL DE DIDÁTICA E PRÁTICA DE ENSINO, 2000, Rio de Janeiro. Linguagens, espaços e tempos no ensinar e no aprender. Rio de Janeiro: DP\&A, 2000 .

GARCÍA, J. Eduardo. Los problemas de la educación ambiental: ¿es posible una educación ambiental integradora? Investigación en la escuela. Sevilha: Díada Editora S. L, 2002. p. 5-25. Nuevas tendencias de la Educación Ambiental, n. 46.

GOUVÊA, Guaracira e LEAL, Maria C. Uma visão comparada do ensino em ciência, tecnologia e sociedade na escola e em um museu de ciência. Revista Ciência \& Educação, v. 7, n.1 p. 67-84, maio, 2001.

GORDILLO, Mariano M. AIDS-2001: la vacuna contra el SID A. Simulación educativa de un caso CTS sobre la salud. Madrid: Organização dos Estados Iberoamericanos para la Educación, la Ciencia y la Cultura (OEI), 2001. 
GRÜN, Mauro. Ética e educação ambiental: A conexão necessária. Campinas, SP: Papirus, 1996.

JIMÉNEZ ALEIXANDRE, Maria P. Discurso de aula y argumentación en la clase de ciências. In: CONGRESO ENSEÑANZA DE LAS CIÊNCIAS, 2001, Barcelona. p. $1-16$.

MUÑOZ, María C. G. Principales tendencias y modelos de la Educación Ambiental en el sistema escolar. Revista Iberoamericana de Educación, Madrid n.11, p. 13-74, 1996.

OLIVEIRA, Marta Kohl de. Vygotsky: aprendizado e desenvolvimento: um processo sócio-histórico. São Paulo: Scipione, 1993.

ORELLANA, Isabel. La estrategia pedagógica de la comunidad de aprendizaje, definiendo sus fundamentos, sus prácticas y su pertinencia en educación ambiental. In SAUVÉ, L., ORELLANA, I. e SATO, M. Textos escogidos en Educación ambiental, de una América a la otra, Tomo 2, ERE-UQAM, Université du Québec, Montreal, 2002.

OSÓRIO, Carlos M. La Educación Científica y Tecnológica desde el enfoque en Ciencia, Tecnología y Sociedad. Aproximaciones y Experiencias para la Educación Secundaria. Revista Iberoamericana de Educación, Madrid, n. 28, enero-abril 2002. Disponível em: <http://www.campus-oei.org/salactsi/osorio3.htm>. Acesso em: 06 mar. 2002.

PEREIRA, Luiza H. Análise de conteúdo: um approach do social. In NEVES, Clarissa E. B; CORRÊA, Maíra B. Cadernos de Sociologia. Porto Alegre, v. 9, p. 87-114, 1998.

PERELMAN, Chaïm; OLBRECHTS-TYTECA, Lucie. Tratado da argumentação: a nova retórica. Tradução: Maria Ermantina Galvão Pereira. São Paulo: Martins Fontes, 1996.

REIGOTA, Marcos. O que é educação ambiental. São Paulo: Brasiliense, 1998. 
SANMARTI, Neus; PUJOL, Rosa M. Qué comporta "capacitar para la acción” en el marco de la escuela? Investigación en la escuela. Sevilla: Díada Editora S.L, 2002. p. 49-54. Nuevas tendencias de la Educación Ambiental, n.46.

SANTOS, Boaventura S. Um discurso sobre as ciências. 10ª ed. Porto: Afrontamento, 1998.

SANTOS, Wildson. L. P.; MORTIMER, Eduardo F. Tomada de decisão para ação social responsável no ensino de ciências. Revista Ciência \& Educação, São Paulo v. 7, n. 1, p. 95-112, maio 2001.

VALDÉS, Pablo et al. Implicaciones de las relaciones ciencia-tecnología en la educación científica. Revista Iberoamericana de Educación, Madrid, n. 28, enero-abril 2002. Disponível em: <www.campus.oei.org/salactsi/revista/rie28a04.htm>. Acesso em: 11 jul. 2002. 